\title{
B-cell activating factor receptor expression is associated with germinal center B-cell maintenance
}

\author{
FRANCISCO JOSUÉ CARRILLO-BALLESTEROS ${ }^{1}$, EDITH OREGON-ROMERO ${ }^{1}$, \\ RAMON ANTONIO FRANCO-TOPETE ${ }^{2}$, LUIS HUMBERTO GOVEA-CAMACHO ${ }^{3}$, \\ ALVARO CRUZ ${ }^{1}$, JOSÉ FRANCISCO MUÑOZ-VALLE ${ }^{1}$, FELIPE JESÚS BUSTOS-RODRÍGUEZ ${ }^{2}$, \\ ANA LAURA PEREIRA-SUÁREZ ${ }^{4}$ and CLAUDIA AZUCENA PALAFOX-SÁNCHEZ ${ }^{1}$ \\ ${ }^{1}$ Research Institute of Biomedical Sciences, Department of Medical Clinics; ${ }^{2}$ Department of Microbiology and \\ Pathology, University Center for Health Sciences, University of Guadalajara; \\ ${ }^{3}$ Department of Otorhinolaryngology, West National Medical Center, Mexican Institute of Social Security; \\ ${ }^{4}$ Department of Physiology, University Center for Health Sciences, University of Guadalajara, \\ Guadalajara, Jalisco 44340, México
}

Received April 26, 2018; Accepted November 23, 2018

DOI: $10.3892 / \mathrm{etm} .2019 .7172$

\begin{abstract}
B-cell activating factor (BAFF) is a major cytokine that regulates B-cell survival, maturation and differentiation through its binding with its receptors: BAFF receptor (BAFF-R), transmembrane activator and cyclophilin ligand interactor (TACI) and B-cell maturation antigen (BCMA). These receptors have been demonstrated to be involved in tertiary lymphoid structure formation; however, their role in germinal centers (GCs) has remained elusive. The aim of the present study was to determine the expression profiles of BAFF and its receptors in secondary lymphoid tissues. Tonsils resected due to chronic tonsillitis were used as lymphoid tissues. To confirm the presence of GCs identified based on their typical structure, CD21 antibody staining was employed. The expression of BAFF, BAFF-R, TACI and BCMA was assessed by immunohistochemistry. BAFF was highly expressed in all regions of the follicle, but the highest BAFF expression was detected in the mantle zone (MZ). A high expression of BAFF-R was observed on lymphocytes in the $\mathrm{MZ}$ in comparison with the other regions $(\sim 80 \% ; \mathrm{P}<0.05)$, which was co-localizated with BAFF $(\mathrm{r}=0.646 ; \mathrm{P}<0.001)$, in the MZ. TACI and BCMA exhibited similar expression among the different zones of the GCs, and co-localization with BAFF
\end{abstract}

Correspondence to: Dr Claudia Azucena Palafox-Sánchez, Research Institute of Biomedical Sciences, Department of Medical Clinics, University Center for Health Sciences, University of Guadalajara, 950 Sierra Mojada, Edificio Q, Guadalajara, Jalisco 44340, México

E-mail:kklaumx@yahoo.com

Key words: B-cell activating factor, B-cell activating factor receptor, transmembrane activator and cyclophilin ligand interactor, B-cell maturation antigen, expression, germinal centers was observed inside the follicle, mainly in the dark zone. The present results indicate that BAFF is implicated in the maintenance of GCs. BAFF-R overexpression in the MZ, co-localizated with BAFF, suggests that these proteins constitute the principal pathway for the maintenance of the naïve B-cell population. Furthermore, TACI and BCMA have a role in the GC, where processes of B-cell selection, proliferation and differentiation into immunoglobulin-secreting plasma cells occur.

\section{Introduction}

B-cell activating factor (BAFF), also known as B-lymphocyte stimulator, is a cytokine belonging to the tumor necrosis factor ligand superfamily, existing either as a type 2 transmembrane protein or in its soluble form (1). BAFF and its homolog A PRoliferation-Inducing Ligand (APRIL) have an important role in B-cell maturation, survival, selection and differentiation (2). The major sources for BAFF cytokine are several innate immune cell types, including monocytes, macrophages (3), neutrophils (4) and dendritic cells in response to Toll-like receptors, type I and II interferons (IFNs) (5), interleukin-10 (6) and granulocyte colony-stimulating factor expression (7). Furthermore, fibroblast-like cells (8) and astrocytes (9) are also able to produce BAFF, and so are B cells (10) and T cells (11) in secondary lymphoid tissues, including the spleen, lymph nodes and tonsils. Increased levels of BAFF have been associated with autoimmune diseases (12), including systemic lupus erythematosus (13), Sjögren's syndrome (14) and rheumatoid arthritis (15), as well as with multiple myeloma (16), non-Hodgkin's lymphoma (17), B-lineage lymphomas (18) and Hodgkin's lymphoma (19).

A total of 3 BAFF-binding receptors have been established, namely BAFF receptor (BAFF-R), which is specific for BAFF, and two others that are shared with the homologue APRIL, transmembrane activator and cyclophilin ligand interactor (TACI) and B-cell maturation antigen 
(BCMA) (2). BAFF-R is essential for B-cell maturation at early transitional stages, particularly from T1 to T2 B cells, as well as for B-cell survival (20). TACI is important for T-cell-independent responses of B cells, immunoglobulin (Ig) class switch and it is considered to be a negative regulator of B-cell homeostasis (21-23). Whereas, BCMA promotes plasma cells survival (24). All three BAFF receptors, BAFF-R, TACI and BCMA, are expressed on B cells; TACI is additionally expressed on activated T cells, while BAFF-R is also expressed on follicular helper $\mathrm{T}$ cells $\left(\mathrm{T}_{\mathrm{FH}}\right)(21,25)$.

Germinal centers (GCs) are important structures in secondary lymphoid tissues where $\mathrm{T}$ cell-dependent immune responses occur, and BAFF has been identified to be implicated in their formation from lymphoid tissues in murine models $(26,27)$, as well as in tertiary lymphoid structures in autoimmune diseases $(28,29)$. A study reported that BAFF and APRIL are associated with artery tertiary lymphoid organs in giant-cell arteritis, and that BAFF is highly expressed within infiltrating, vascular and endothelial cells, suggesting their involvement in ectopic GCs; however, BAFF receptors were not analyzed (28). Likewise, in Hodgkin (30) and non-Hodgkin lymphoma (31), the BAFF/BAFF-R pathway has an important role and has been proposed as a predictor of lymphoma development in primary Sjögren's syndrome (32). However, only few studies have assessed the expression of BAFF receptors in non-neoplastic lymphoid tissues in humans $(30,33,34)$. Therefore, the distribution and expression profiles of BAFF and their receptors, BAFF-R, TACI and BCMA, in secondary follicles from tonsil tissues were analyzed in the present study.

\section{Materials and methods}

Patients. Tonsils were obtained from nine patients submitted to a routine tonsillectomy performed at the Department of Otorhinolaryngology of the Mexican Institute of Social Security (Guadalajara, Mexico). The mean age of the patients was 12 years (range, 4-41 years), and the cohort comprised 7 females and 2 males. The clinical diagnosis for the majority of the patients was chronic tonsillitis and grade III or IV tonsillar hypertrophy. All of the patients, or their guardians in the case of minors, provided written informed consent in accordance with the Declaration of Helsinki and the current national guidelines and regulations. The ethics committee of the University Center for Health Sciences, University of Guadalajara (Guadalajara, Mexico) approved the study under the number CI-01215.

Histological technique and characterization of GCs. Palatine tonsils were fixed in $4 \%$ paraformaldehyde for later paraffin embedding using a tissue processor (TP1020; Leica Biosystems, Wetzlar, Germany). Tissues were sectioned at 4 microns and mounted on electrocharged slides. After drying, slides were de-paraffinized in an electric oven at $59^{\circ} \mathrm{C}$, re-hydrated in xylene and a series of graded ethanols followed by distilled water. Haematoxylin-eosin staining was performed in order to identify GC morphology in tonsils. A total of four zones in GCs were identified and considered in the expression analysis: The dark zone (DZ), where lymphocytes have a large nucleus and a small amount of cytoplasm; the light zone (LZ), where lymphocytic cells with a higher amount of cytoplasm may be distinguished due to their differentiation; the mantle zone (MZ), consisting of a lymphocyte fringe that surrounds the $\mathrm{GC}$ and exhibits an asymmetric distribution regarding the central axis to the follicle; and the interfollicular zone (IZ) as the remaining area excluding the GCs. Finally, the presence of GCs was immunohistochemically confirmed by CD21 labeling and as described below.

Immunohistochemical staining. Once tissue sections were re-hydrated, antigen retrieval was accomplished in one step with a water steamer at 96 degrees for $30 \mathrm{~min}$, while slides were submerged in a cup with $10 \mathrm{mM}$ sodium citrate buffer $(\mathrm{pH}=6)$ for later staining with rat monoclonal antibody to BAFF (cat. no. ab16081; dilution, 1:100), rabbit monoclonal antibodies to TACI (cat. no. ab79023; dilution, 1:200) and BCMA (cat. no. ab5972; dilution, 1:400), or $1 \mathrm{mM}$ EDTA buffer $(\mathrm{pH}=9)$ for later staining with mouse monoclonal antibodies to CD21 (cat. no. ab9492; dilution, 1:10) and BAFF-R (cat. no. ab16232; dilution, 1:500) from Abcam (Cambridge, UK). After cooling, slides were treated with a peroxidase blocking solution composed of $3 \%$ hydrogen peroxide and $10 \%$ methanol solution for $15 \mathrm{~min}$ at room temperature. The slides were then blocked with serum depending on the secondary antibody source: Horse serum for CD21 and BAFF-R; rabbit serum for BAFF; and goat serum for TACI and BCMA antibodies (VECTASTAIN Elite ABC-HRP Kit; Vector Laboratories, Inc., Burlingame, CA, USA). The samples were incubated with the primary antibodies overnight at $4^{\circ} \mathrm{C}$. Detection was performed with the respective provided secondary biotinylated antibody (1:200), for $30 \mathrm{~min}$ at room temperature and streptavidin (VECTASTAIN Elite ABC-HRP Kit; Vector Laboratories, Inc.) using diaminobenzidine (DAB) until a red-brown color developed. Finally, counterstaining was performed using Harris' hematoxylin.

Immunohistochemistry slide staining for CD3 and CD20 was performed using the automated Ventana Benchmark ULTRA (Roche Diagnostics, Basel, Switzerland) following the manufacturer's recommended protocols for paraffin-embedded sections. The primary antibodies anti-CD3 (2GV6) rabbit monoclonal antibody (cat. no. 790-4341) and anti-CD20 (L26) mouse monoclonal antibody [cat. no. 760-2531; Ventana iVIEW PATHWAY (Roche Diagnostics) were obtained prediluted by Roche Diagnostics, and were optimized for use on Ventana staining platforms. Detection was performed with the iVIEW DAB detection kit (Roche Diagnostics)].

Immunohistochemical image analysis. After staining, images of the slides were captured with a digital camera (Axiocam 305; Zeiss AG, Oberkochen, Germany) attached to an optical microscope (Axio Lab.A1; Zeiss AG) and three fields of view per slide were tested with a total magnification of $x 400$ for each case; the same three fields of view were captured for the analyzed surface area from each sample. AxioVision V4.6 software (Zeiss AG) was used for controlling the light and camera settings. Image analysis was performed using ImageJ v1.51j8 free software (National Institutes of Health, Bethesda, MD, USA; http://imagej.nih.gov/ij/) using the DAB color deconvolution plugin. In the DAB layer, the analysis of tissue images was performed considering the pixel intensity values in the range of $0-255$, as previously described by Chatterjee et al (35). The mean intensity was identified using ImageJ software using the mean default threshold feature in 
A

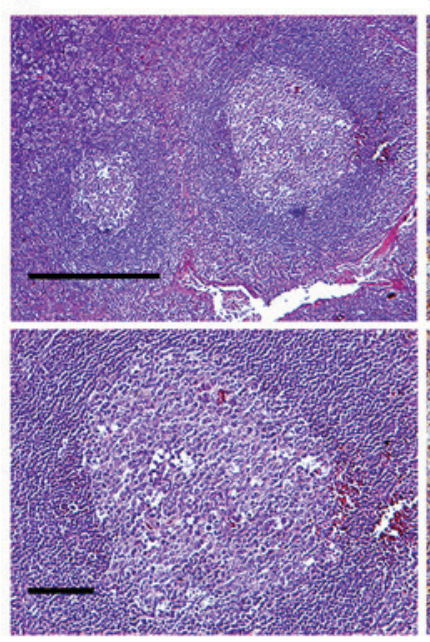

B

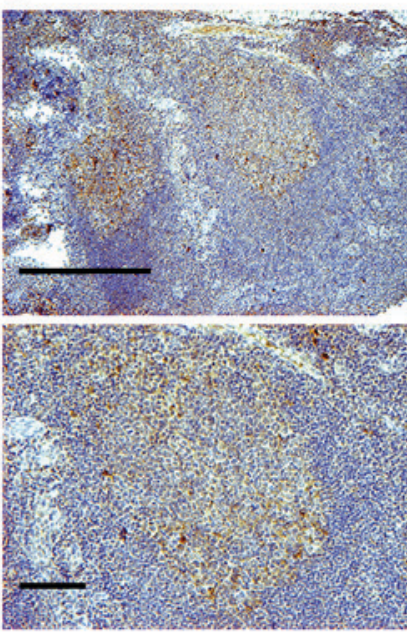

$\mathrm{C}$

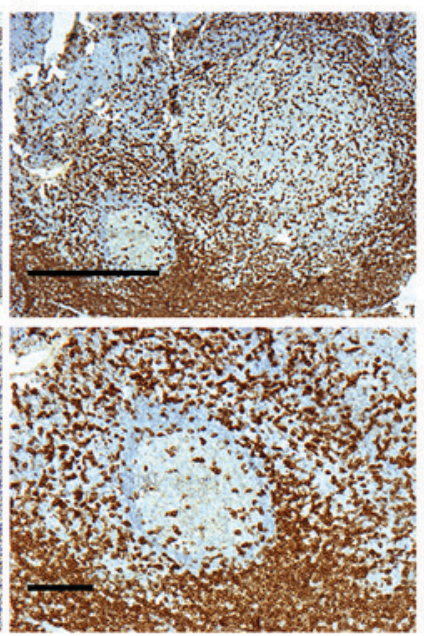

$\mathrm{D}$

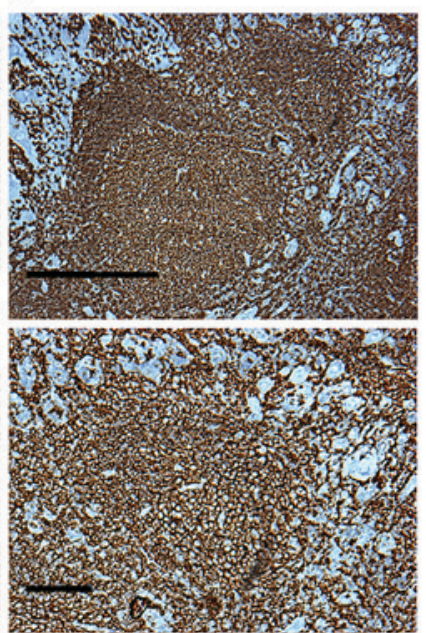

Figure 1. Identification of cell subtypes in germinal centers. (A) Haematoxylin and eosin staining, (B) CD21 staining for follicular dendritic cells, (C) CD3 staining for T cells and (D) CD20 staining for B cells of in human tonsil tissues (magnification, x50 and x100; scale bars, 400 and $200 \mu \mathrm{m}$, in the upper and lower panel, respectively).

the 'Image' menu. Finally, the number of positive pixels in a zone was measured with the measuring tool 'Analyze' from the software menu. The staining quantification was the mean percentage of stained cells in the field of view.

Statistical analysis. Statistical analysis was performed using GraphPad Prism 6 software (GraphPad Software Inc., La Jolla, CA, USA). Data were analyzed using the Shapiro-Wilk normality test and $95 \%$ confidence interval. $\mathrm{P}<0.05$ was considered to indicate a statistically significant difference. For multiple-group comparisons with parametric data, one-way analysis of variance and Tukey's post-hoc test was used. Correlation analyses were performed using Pearson's $\mathrm{R}^{2}$ correlation coefficients.

\section{Results}

Identification of GCs in tonsillar follicles based on CD21 expression. Besides their morphological features and the typical structure of a secondary lymphoid organ (Fig. 1A and B), immunohistochemical staining for CD21 was used for locating GCs in tonsillar secondary lymphoid tissue, in order to identify the presence of follicular dendritic cell networks. CD21-positive cells were observed mainly in the LZ. The MZ presented with diffuse staining for CD21 (Fig. 1C and D).

Identification of CD3+ and CD20+ cells of GCs in tonsillar follicles. The cellular aggregates were further analyzed by staining with anti-CD3 and anti-CD20 antibodies to detect areas of T-cell/B-cell aggregation (Fig. 1C and D). CD3+ cells were located mainly in IZs as well as in the LZ and DZ. A small amount of CD3+ cells were observed in the MZ (Fig. 1C). However, CD20+ cells were the most remarkable cell type in the entire tonsillar follicles (Fig. 1D).

Expression of BAFF in human tonsils. BAFF expression was examined in GCs from human tonsils. BAFF was highly expressed in all regions of the GC. However, the highest percentage of BAFF+ cells, exhibiting a membrane and intracellular staining pattern, were located in the $\mathrm{MZ}$ corresponding to the naïve B-cell area $(\mathrm{P}<0.05$ vs. LZ, DZ and IZ; Fig. 2A, D and F).

Analysis of BAFF-R expression in human tonsils. Based on the average staining intensities and percentages of positively stained cells, a high expression of BAFF-R was observed in the membrane cells of the $\mathrm{MZ}(\mathrm{P}<0.05$ vs. DZ, LZ and IZ; Fig. 3A-F). The lowest expression of BAFF-R was identified in the IZ (Fig. 3A, E and F).

Analysis of TACI expression in human tonsils. TACI-expressing cells were mostly located inside GCs in the DZ and LZ, and also in the MZ. No significant differences in TACI+ cells were observed among the different GC areas (Fig. 4A-F).

Analysis of BCMA expression in human tonsils. BCMA exhibited a similar distribution between the DZ, LZ and MZ (Fig. 5A-F). The lowest expression of BCMA was observed in the IZ $(\mathrm{P}<0.05$ vs. DZ, LZ and MZ; Fig. 5A, E and F). In addition, a small proportion of cells expressing BCMA in the tonsillar submucosa, particularly in proximity to blood vessels, were observed (data not shown).

Association between BAFF and its receptors in $G C$ zones. The association between $\mathrm{BAFF}$ and its receptors regarding their distribution in GC zones was analyzed. A co-localization of BAFF and BAFF-R according to amount of positive cells and staining intensity was identified in the $\mathrm{DZ}(\mathrm{r}=0.401, \mathrm{P}=0.038$; Fig. 6A) and the $\mathrm{MZ}(\mathrm{r}=0.646, \mathrm{P}<0.001$; Fig. 6B).

Regarding the TACI receptor, a positive correlation with BAFF levels was identified in the $\mathrm{DZ}(\mathrm{r}=0.456, \mathrm{P}=0.017$; Fig. $6 \mathrm{C})$.

With regard to BCMA, BAFF+ cells were correlated with the amount of BCMA+ cells in the DZ $(r=0.736, P<0.001$; Fig. 6D), LZ (r=0.495, $\mathrm{P}=0.009$; Fig. 6E) and $\mathrm{IZ}(\mathrm{r}=0.513$, $\mathrm{P}=0.006$; Fig. 6F). 

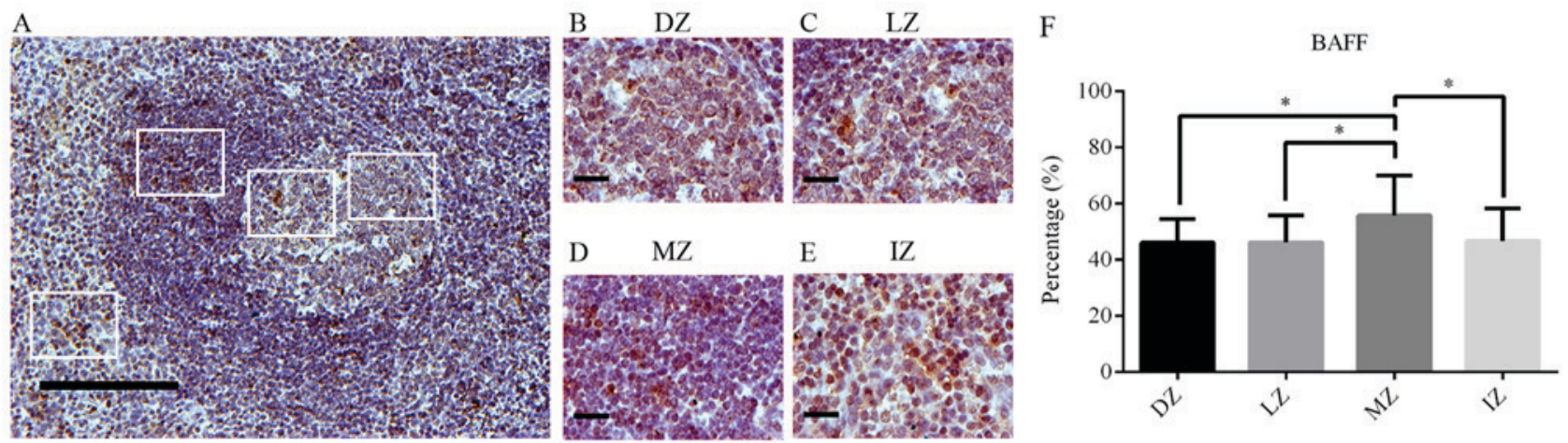

Figure 2. BAFF expression in germinal centers. (A) BAFF staining in human tonsils (magnification, x100; scale bar, 200 $\mu$ m). (B-E) BAFF staining in (B) the DZ, (C) LZ, (D) MZ and (E) IZ in germinal centers of human tonsils (magnification, $\mathrm{x} 400$; scale bar, $50 \mu$ m). (F) Percentage of BAFF-positive cells in different zones of germinal centers in human tonsils. BAFF expression is showed as brown-orange staining and Harris' hematoxylin was used as a blue-purple counterstain. Images were quantitatively analyzed using ImageJ software. Values are expressed as the mean \pm standard deviation. ${ }^{*} \mathrm{P}<0.05$. DZ, dark zone; IZ, interfollicular zone; LZ, light zone; MZ, mantle zone; BAFF, B-cell activating factor.
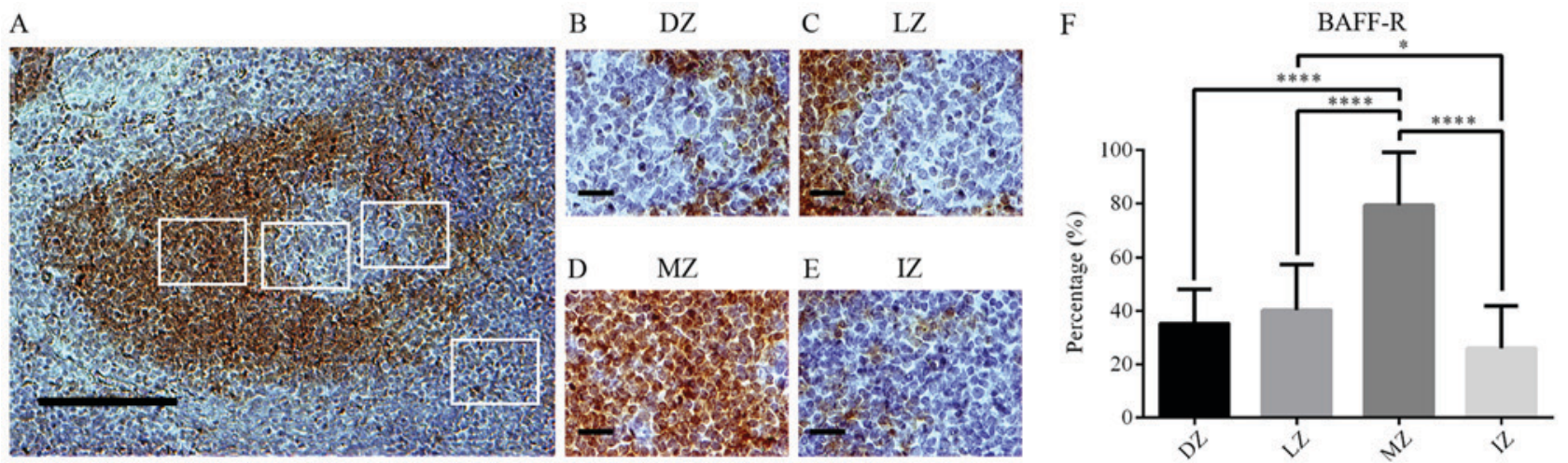

Figure 3. BAFF-R expression in germinal centers. (A) BAFF-R staining in human tonsils (magnification, x100; scale bar, $200 \mu \mathrm{m}$ ). (B-E) BAFF-R staining in (B) the DZ, (C) LZ, (D) MZ and (E) IZ in germinal centers of human tonsils (magnification, x400; scale bar, $50 \mu$ m). (F) Percentage of BAFF-R-positive cells in different zones of germinal centers in human tonsils. BAFF-R expression is showed as brown-orange staining and Harris' hematoxylin was used as a blue-purple counterstain. Images were quantitatively analyzed using ImageJ software. Values are expressed as the mean \pm standard deviation. ${ }^{*} \mathrm{P}<0.05$;

${ }^{* * *} \mathrm{P}<0.0001$. DZ, dark zone; IZ, interfollicular zone; LZ, light zone; MZ, mantle zone; BAFF-R, B-cell activating factor receptor.

\section{Discussion}

BAFF is a key molecule that mediates B-cell survival, proliferation and differentiation through its receptors BAFF-R, TACI and BCMA in different stages of B-cell development (2). $\mathrm{BAFF}$ and BAFF-binding receptors have been demonstrated to be involved in the formation of GCs in secondary follicles in murine models and in tertiary lymphoid structures in autoimmune diseases $(28,26,27)$. GCs are the major sites for the generation of high-affinity antibody-secreting plasma cells and memory B cells, through the processes of proliferation, high-affinity selection and somatic hypermutation $(36,37)$. GCs are well-organized structures with defined histological zones referred to as the $\mathrm{DZ}, \mathrm{LZ}$ and $\mathrm{MZ}$, while the remaining area is known as the IZ (38). In the present study the expression profiles of BAFF and their receptors, BAFF-R, TACI and BCMA, were analyzed in secondary follicles from human tonsillar tissues.

A diffuse expression of BAFF was identified in extended tonsillar tissue areas, particularly in the MZ, where the highest percentages of BAFF+ cells were located. The BAFF expression profiles may be explained by the large abundance of BAFF-secreting cells in the lymphoid tissue, mainly follicular dendritic cells $(39,40)$ and $\mathrm{T}_{\mathrm{FH}}$ cells $(41)$, which are the major sources of BAFF. However, numerous other types of myeloid origin cell, including monocytes, macrophages and neutrophils, are important for BAFF-producing cells $(42,43)$. Furthermore, it has been demonstrated in experimental models that BAFF is necessary for GC formation, since BAFF blockade with anti-BAFF-R antibodies decreases the number of follicles in mouse secondary lymphoid organs (44).

In the present study, expression of the three BAFF receptors, BAFF-R, TACI and BCMA, was detected in the GCs of the secondary follicles from human tonsil tissues. However, a different expression pattern was observed among them. In addition, a correlation between BAFF and each of the three BAFF-binding receptors was observed, particularly in the DZ of GCs. This result may be due to the function of BAFF as a survival factor for centroblasts, which are highly proliferating cells that are about to undergo selection, clonal expansion and somatic hypermutation (45).

BAFF-R expression was observed inside GCs; furthermore, a high expression was observed in the MZ. In this region, mainly $\operatorname{IgD}+$ naïve $B$ cells are located $(30,46)$, which suggests that this receptor is essential at early stages 


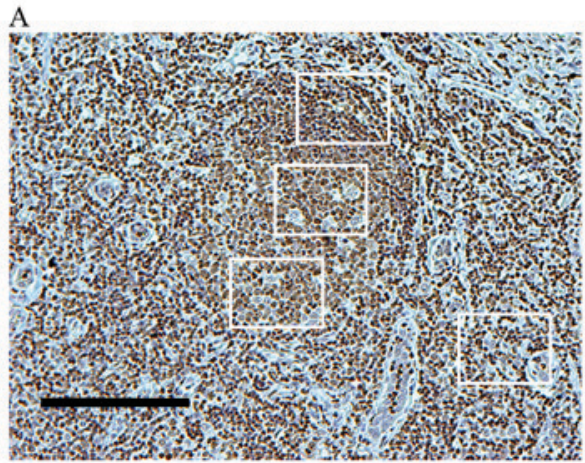

B DZ

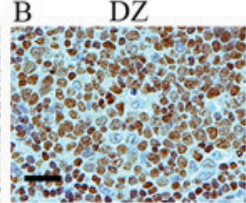

D
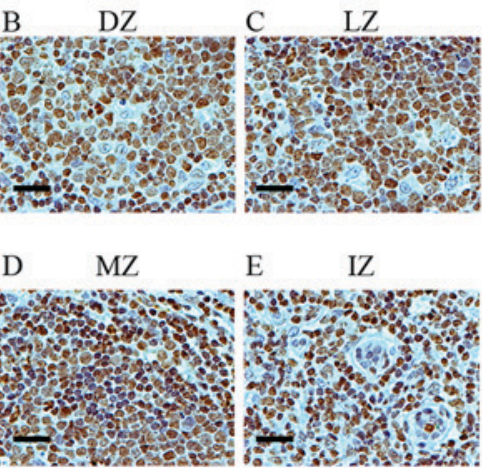

$\mathrm{F}$

TACI

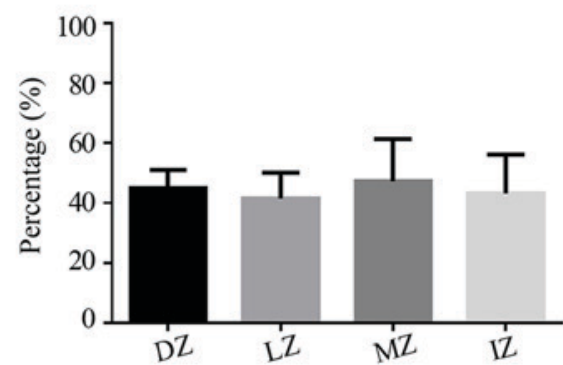

Figure 4. TACI expression in germinal centers. (A) TACI staining in human tonsils (magnification, x100; scale bar, $200 \mu$ m). (B-E) TACI staining in (B) the DZ, (C) LZ, (D) MZ and (E) IZ in germinal centers of human tonsils (magnification, $\mathrm{x} 400$; scale bar, $50 \mu \mathrm{m}$ ). (F) Percentage of TACI-positive cells in different zones of germinal centers in human tonsils. TACI expression is showed as brown-orange staining and Harris' hematoxylin was used as a blue-purple counterstain. Images were quantitatively analyzed using ImageJ software. Values are expressed as the mean \pm standard deviation. No statistically significant differences. DZ, dark zone; IZ, interfollicular zone; LZ, light zone; MZ, mantle zone; TACI, transmembrane activator and cyclophilin ligand interactor.

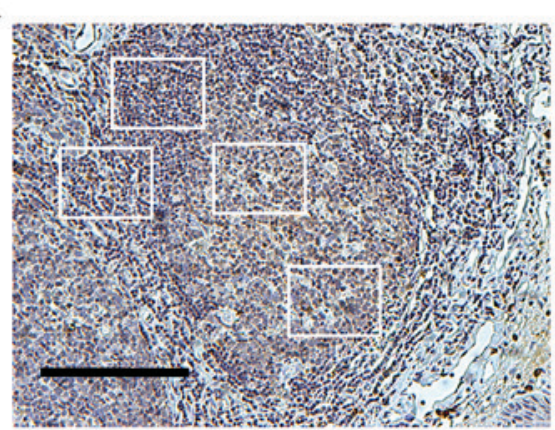

B

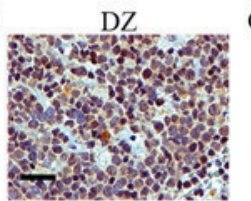

$\mathrm{D}$

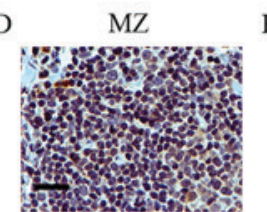

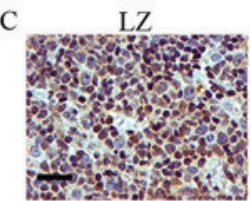

$\mathrm{E}$

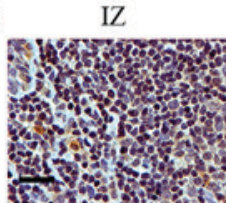

$\mathrm{F} \quad \mathrm{BCMA}$

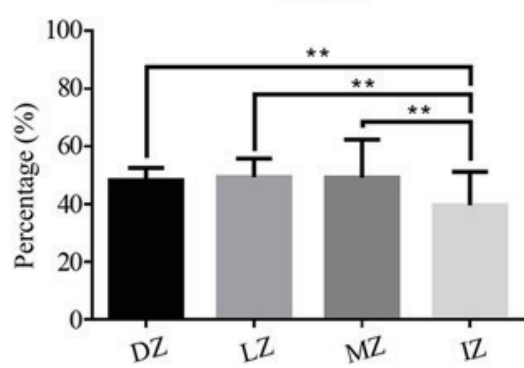

Figure 5. BCMA expression in germinal centers. (A) BCMA staining in human tonsils (magnification, x100; scale bar, $200 \mu \mathrm{m}$ ). (B-E) BCMA staining in (B) the DZ, (C) LZ, (D) MZ and (E) IZ in germinal centers of human tonsils (magnification, x400; scale bar, $50 \mu \mathrm{m}$ ). (F) Percentage of BCMA-positive cells in different zones of germinal centers in human tonsils. BCMA expression is showed as brown-orange staining and Harris' hematoxylin was used as a blue-purple counterstain. Images were quantitatively analyzed using ImageJ software. Values are expressed as the mean \pm standard deviation. ${ }^{* *} \mathrm{P}<0.01$. DZ, dark zone; IZ, interfollicular zone; LZ, light zone; MZ, mantle zone; BCMA, B-cell maturation antigen.
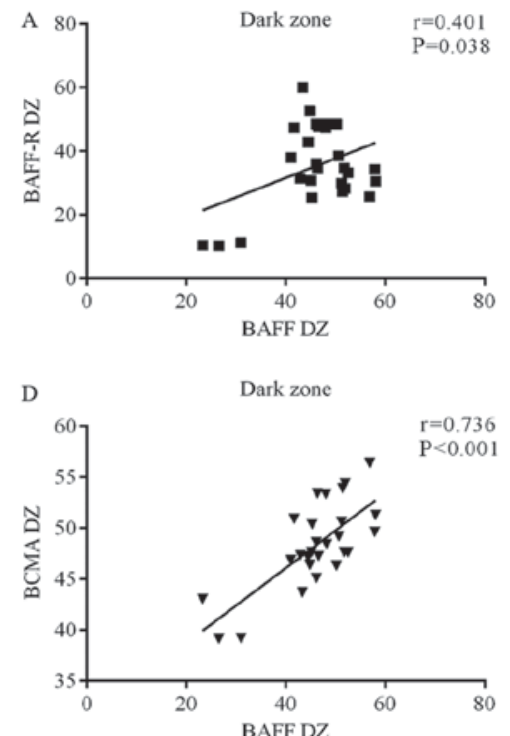

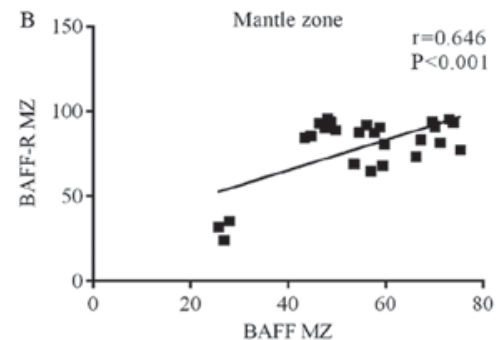

E

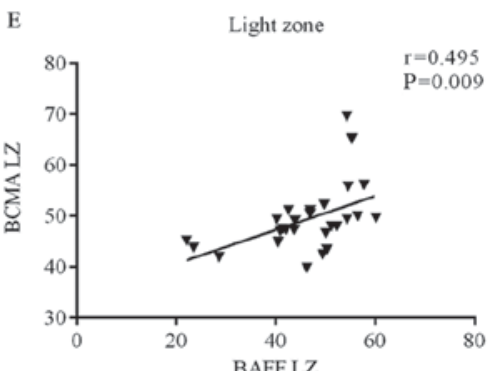

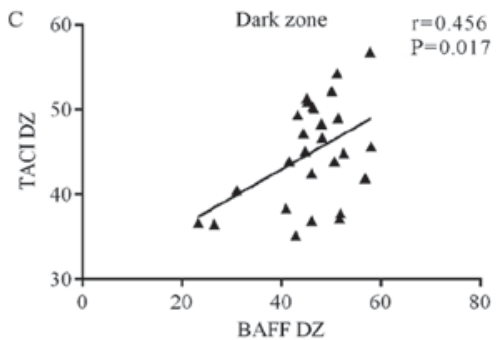

$\mathrm{F}$

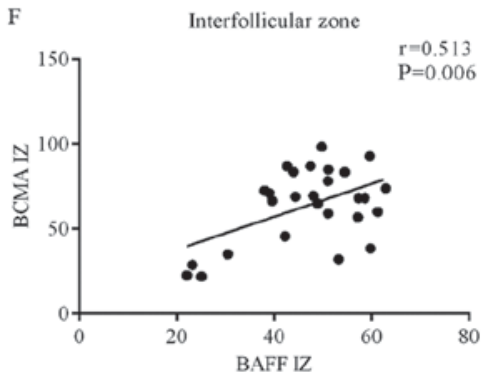

Figure 6. Correlations between BAFF and BAFF-binding receptors in germinal centers of human tonsils. (A) Positive correlation between BAFF and BAFF-R expression levels in the DZ of germinal centers. (B) Positive correlation between BAFF and BAFF-R expression levels in the MZ of germinal centers. (C) Positive correlation between BAFF and TACI expression levels in the DZ of germinal centers. (D) Positive correlation between BAFF and BCMA expression levels in the DZ of germinal centers. (E) Positive correlation between BAFF and BCMA expression level at LZ in germinal centers. (F) Positive correlation between BAFF and BCMA expression level at IZ in germinal centers from human tonsils. Statistical analysis was performed using Pearson's $r$ correlation. DZ, dark zone; IZ, interfollicular zone; LZ, light zone; MZ, mantle zone; TACI, transmembrane activator and cyclophilin ligand interactor; BCMA, B-cell maturation antigen; BAFF-R, B-cell activating factor receptor. 
of B-cell development and promotes their maturation (47). Furthermore, the most evident BAFF and BAFF-R interaction was identified in the $M Z$, which was greater than that in the LZ and DZ. BAFF-R has been previously detected on B-cells situated in the MZ (33). Furthermore, an in vitro study that analyzed GC B cell maturation indicated an initial increment of BAFF-R expression in early stages, which decreased during plasma cell differentiation, and was associated with TACI and BCMA expression (34). Recently, it has been proposed that GC B cells from the DZ, express lower levels of BAFF-R due to the cleavage process of BAFF-R by A disintegrin and metalloproteinases, a BAFF- and TACI-dependent mechanism (48).

In addition, $\mathrm{T}$ cells in the MZ and inside follicles were observed in the present study, although at a lower proportion compared with that of B cells. It has been demonstrated that $\mathrm{T}$ cells are able to express BAFF-R favoring T-cell activation and their differentiation to $\mathrm{T}_{\mathrm{FH}}$ (49). In fact, an expansion of $\mathrm{T}_{\mathrm{FH}}$ with high IFN- $\gamma$ production through BAFF-R was observed in a lupus-prone murine model with BCMA deficiency, which suggests a potential role of a BCMA-BAFF-R balance in the maintenance of immune tolerance (25).

However, the expression pattern of TACI identified in the present study displayed a wide distribution within follicles from the tonsillar tissue. TACI has been linked to isotype class switch in T-independent immune responses and it is perceived as a negative regulator of B cells (21). These results are supported by a previous experimental study on TACI gene knockout (KO) mice, which revealed expanding populations of $\mathrm{T}_{\mathrm{FH}}$ and GC B cells in their spleens when immunized with a T-cell-dependent antigen. In addition, TACI KO mice exhibited decreased plasma cells and antigen-specific antibody responses (50).

In addition, a correlation between TACI and BAFF was observed in the DZ, but not in the $\mathrm{LZ}$ within the follicle, whereas a correlation of BCMA and BAFF was observed in the DZ as well as the LZ. BAFF shares TACI and BCMA receptors with APRIL, which also co-stimulates $B$ cells and plasma cell survival; however, APRIL expression was not evaluated in the present study.

It is likely that the BCMA-TACI interaction is a key mechanism in B-cell differentiation to plasma cells in the LZ. As demonstrated by a previous study using a Nba2.Yaa spontaneous lupus mouse model with induced TACI, BCMA or double TACI-BCMA mutations, the disease activity was increased in BCMA-deficient animals, while it was decreased in animals with TACI deficiency and TACI-BCMA double deficiency (51).

BCMA is expressed on B cells, plasmablasts and GC plasma cells (52). In a murine lupus model, BCMA deficiency was associated with early lethality. Exacerbated B cell and plasma cell production and increased autoantibody levels reveal that BCMA is key in the maintenance of B-cell homeostasis and self-tolerance control in autoimmunity responses (53). The presence of BCMA-expressing cells within tonsillar follicles emphasizes its possible role in the differentiation process towards antibody-producing plasma cells, which migrate to regions near blood vessels or salivary conducts to secrete mucosa-associated Igs, e.g. IgA. This explains why BCMA was associated with BAFF in cells located in the IZ.
In conclusion, the high expression and differential distribution patterns of BAFF, BAFF-R, TACI and BCMA in follicle zones suggest their involvement in the maintenance of GCs in tonsillar secondary lymphoid tissue. BAFF-R overexpression in the $\mathrm{MZ}$ associated with BAFF suggests that BAFF, through BAFF-R, is the principal pathway for maintaining the population of naïve B-cells in GCs. Furthermore, TACI and BCMA have roles inside GCs, where processes of $\mathrm{B}$-cell positive selection, proliferation and differentiation into Ig-secreting plasma cells occur.

\section{Acknowledgements}

Not applicable.

\section{Funding}

This work was supported by a grant no. 273324 to EOR, from the National Council of Science and Technology (CONACYT).

\section{Availability of data and materials}

All data generated or analyzed during this study are included in this published article.

\section{Authors' contributions}

FJCB: Patient enrollment, immunohistochemistry assay, immunohistochemical quantification and statistical analysis, manuscript preparation; EOR: Manuscript preparation, statistical analysis and study design; RAFT: Histological technique and GC evaluation; LHGC: Patient enrollment, surgical tissues obtention and histological technique; FJBR: Histological technique and GC evaluation; ALPS: Immunohistochemical quantification analysis; AC: Immunohistochemical quantification analysis and manuscript preparation; JFMV: Manuscript preparation and analysis and interpretation of data; CAPS: Patient enrollment, clinical evaluation, statistical analysis, manuscript preparation and study design. All authors read and approved the final version of the manuscript.

\section{Ethics approval and consent to participate}

In accordance with the Declaration of Helsinki and the current national guidelines and regulations, written informed consent was provided by all of the patients, and in the case of minors under the age of 16 years, the parents provided written informed consent. The ethics committee of the University Center for Health Sciences, University of Guadalajara (Guadalajara, Mexico) approved the study under the number CI-01215.

\section{Patient consent for publication}

Not applicable.

\section{Competing interests}

The authors declare that they have no competing interests regarding the present study. They have no relationship with or 
any financial interests regarding any commercial companies pertaining to this article.

\section{References}

1. Vincent FB, Saulep-Easton D, Figgett WA, Fairfax KA and Mackay F: The BAFF/APRIL system: Emerging functions beyond B cell biology and autoimmunity. Cytokine Growth Factor Rev 24: 203-215, 2013.

2. Bossen $\mathrm{C}$ and Schneider P: BAFF, APRIL and their receptors: Structure, function and signaling. Semin Immunol 18: 263-275 2006.

3. Craxton A, Magaletti D, Ryan EJ and Clark EA: Macrophage- and dendritic cell-dependent regulation of human $\mathrm{B}$-cell proliferation requires the TNF family ligand BAFF. Blood 101: 4464-4471, 2003.

4. Scapini P, Bazzoni F and Cassatella MA: Regulation of B-cell-activating factor (BAFF)/B lymphocyte stimulator (BLyS) expression in human neutrophils. Immunol Lett 116: 1-6, 2008.

5. MacLennan I and Vinuesa C: Dendritic cells, BAFF, and APRIL: Innate players in adaptive antibody responses. Immunity 17: 235-238, 2002

6. Ogden CA, Pound JD, Batth BK, Owens S, Johannessen I, Wood K and Gregory CD: Enhanced apoptotic cell clearance capacity and B cell survival factor production by IL-10-activated macrophages: Implications for burkitt's lymphoma. J Immunol 174 3015-3023, 2005.

7. Scapini P, Nardelli B, Nadali G, Calzetti F, Pizzolo G, Montecucco C and Cassatella MA: G-CSF-stimulated neutrophils are a prominent source of functional blys. J Exp Med 197: 297-302, 2003

8. Ohata J, Zvaifler NJ, Nishio M, Boyle DL, Kalled SL, Carson DA and Kipps TJ: Fibroblast-like synoviocytes of mesenchymal origin express functional B cell-activating factor of the TNF family in response to proinflammatory cytokines. J Immunol 174 864-870, 2005

9. Krumbholz M, Theil D, Derfuss T, Rosenwald A, Schrader F, Monoranu CM, Kalled SL, Hess DM, Serafini B, Aloisi F, et al: $\mathrm{BAFF}$ is produced by astrocytes and up-regulated in multiple sclerosis lesions and primary central nervous system lymphoma. J Exp Med 201: 195-200, 2005.

10. Chu VT, Enghard P, Riemekasten G and Berek C: In vitro and in vivo activation induces BAFF and APRIL expression in B cells. J Immunol 179: 5947-5957, 2007.

11. Suzuki K, Setoyama Y, Yoshimoto K, Tsuzaka K, Abe T and Takeuchi T: Effect of interleukin-2 on synthesis of B cell activating factor belonging to the tumor necrosis factor family (BAFF) in human peripheral blood mononuclear cells Cytokine 44: 44-48, 2008.

12. Pers JO, Daridon C, Devauchelle V, Jousse S, Saraux A, Jamin C and Youinou P: BAFF overexpression is associated with autoantibody production in autoimmune diseases. Ann N Y Acad Sci 1050: 34-39, 2005

13. Vincent FB, Morand EF and Mackay F: BAFF and innate immunity: New therapeutic targets for systemic lupus erythematosus. Immunol Cell Biol 90: 293-303, 2012.

14. DaridonC,Devauchelle V,Hutin P,Le BerreR,Martins-CarvalhoC, Bendaoud B, Dueymes M, Saraux A, Youinou P and Pers JO: Aberrant expression of BAFF by B lymphocytes infiltrating the salivary glands of patients with primary Sjögren's syndrome. Arthritis Rheum 56: 1134-1144, 2007.

15. Bosello S, Pers JO, Rochas C, Devauchelle V, De Santis M, Daridon C, Saraux A, Ferraccioli GF and Youinou P: BAFF and rheumatic autoimmune disorders: Implications for disease management and therapy. Int J Immunopathol Pharmacol 20: $1-8,2007$.

16. Pan J, Sun Y, Zhang N, Li J, Ta F, Wei W, Yu S and Ai L: Characteristics of BAFF and APRIL factor expression in multiple myeloma and clinical significance. Oncol Lett 14: 2657-2662, 2017.

17. Novak AJ, Grote DM, Stenson M, Ziesmer SC, Witzig TE, Habermann TM, Harder B, Ristow KM, Bram RJ, Jelinek DF, et al: Expression of BLyS and its receptors in B-cell non-Hodgkin lymphoma: Correlation with disease activity and patient outcome. Blood 104: 2247-2253, 2004.

18. Vaskua BJ, Bienerta P, Kodytkovab D, Zlamala F, Tomandld J, Tomandlovad M, Vaskua A and Sterbab J: BAFF levels are elevated in paediatric patients with acute lymphoblastic leukaemia compared to other B-lineage neoplasms. J Hematol 1: 20-22, 2012
19. Oki Y, Georgakis GV, Migone TS, Kwak LW and Younes A: Prognostic significance of serum B-lymphocyte stimulator in hodgkin's lymphoma. Haematologica 92: 269-270, 2007.

20. Rowland SL, Leahy KF, Halverson R, Torres RM and Pelanda R: BAFF receptor signaling aids the differentiation of immature $\mathrm{B}$ cells into transitional B cells following tonic BCR signaling. J Immunol 185: 4570-4581, 2010.

21. Mackay F and Schneider P: TACI, an enigmatic BAFF/APRIL receptor, with new unappreciated biochemical and biological properties. Cytokine Growth Factor Rev 19: 263-276, 2008.

22. von Bülow GU, van Deursen JM and Bram RJ: Regulation of the T-independent humoral response by TACI. Immunity 14: 573-582, 2001.

23. Yan M, Wang H, Chan B, Roose-Girma M, Erickson S, Baker T, Tumas D, Grewal IS and Dixit VM: Activation and accumulation of B cells in TACI-deficient mice. Nat Immunol 2: 638-643, 2001.

24. O'Connor BP, Raman VS, Erickson LD, Cook WJ, Weaver LK, Ahonen C, Lin LL, Mantchev GT, Bram RJ and Noelle RJ: BCMA is essential for the survival of long-lived bone marrow plasma cells. J Exp Med 199: 91-98, 2004.

25. Coquery CM, Loo WM, Wade NS, Bederman AG, Tung KS, Lewis JE, Hess $\mathrm{H}$ and Erickson LD: BAFF regulates follicular helper $\mathrm{T}$ cells and affects their accumulation and interferon- $\gamma$ production in autoimmunity: BAFF regulates follicular helper T cells. Arthritis Rheumatol 67: 773-784, 2015.

26. Rahman ZS, Rao SP, Kalled SL and Manser T: Normal induction but attenuated progression of germinal center responses in BAFF and BAFF-R signaling-deficient mice. J Exp Med 198: $1157-1169,2003$

27. Vora KA, Wang LC, Rao SP, Liu ZY, Majeau GR, Cutler AH, Hochman PS, Scott ML and Kalled SL: Cutting edge: Germinal centers formed in the absence of B cell-activating factor belonging to the TNF family exhibit impaired maturation and function. J Immunol 171: 547-551, 2003

28. Ciccia F, Rizzo A, Maugeri R, Alessandro R, Croci S, Guggino G, Cavazza A, Raimondo S, Cannizzaro A, Iacopino DG, et al: Ectopic expression of CXCL13, BAFF, APRIL and LT- $\beta$ is associated with artery tertiary lymphoid organs in giant cell arteritis. Ann Rheum Dis 76: 235-243, 2017.

29. Kang S, Fedoriw Y, Brenneman EK, Truong YK, Kikly K and Vilen BJ: BAFF induces tertiary lymphoid structures and positions $\mathrm{T}$ cells within the glomeruli during lupus nephritis. J Immunol 198: 2602-2611, 2017.

30. Chiu A, Xu W, He B, Dillon SR, Gross JA, Sievers E, Qiao X, Santini P, Hyjek E, Lee JW, et al: Hodgkin lymphoma cells express TACI and BCMA receptors and generate survival and proliferation signals in response to BAFF and APRIL. Blood 109: 729-739, 2007.

31. Yang S, Li JY and Xu W: Role of BAFF/BAFF-R axis in B-cell non-hodgkin lymphoma. Crit Rev Oncol Hematol 91: 113-122, 2014.

32. Nocturne G and Mariette X: Sjögren syndrome-associated lymphomas: An update on pathogenesis and management. Br J Haematol 168: 317-327, 2015.

33. Nakamura N, Hase H, Sakurai D, Yoshida S, Abe M, Tsukada N, Takizawa J, Aoki S, Kojima M, Nakamura S and Kobata T: Expression of BAFF-R (BR3) in normal and neoplastic lymphoid tissues characterized with a newly developed monoclonal antibody. Virchows Arch 447: 53-60, 2005.

34. Zhang X, Park CS, Yoon SO, Li L, Hsu YM, Ambrose C and Choi YS: BAFF supports human B cell differentiation in the lymphoid follicles through distinct receptors. Int Immunol 17: 779-788, 2005

35. Chatterjee S, Malhotra R, Varghese F, Bukhari AB, Patil A, Budrukkar A, Parmar V, Gupta S and De A: Quantitative immunohistochemical analysis reveals association between sodium iodide symporter and estrogen receptor expression in breast cancer. PLoS One 8: e54055, 2013.

36. Allen CD, Okada T and Cyster JG: Germinal-center organization and cellular dynamics. Immunity 27: 190-202, 2007.

37. Corcoran LM and Tarlinton DM: Regulation of germinal center responses, memory B cells and plasma cell formation-an update. Curr Opin Immunol 39: 59-67, 2016.

38. Victora GD and Nussenzweig MC: Germinal centers. Annu Rev Immunol 30: 429-457, 2012.

39. Hase H, Kanno Y, Kojima M, Hasegawa K, Sakurai D, Kojima H, Tsuchiya N, Tokunaga K, Masawa N, Azuma M, et al: BAFF/BLyS can potentiate B-cell selection with the B-cell coreceptor complex. Blood 103: 2257-2265, 2004 
40. Suzuki K, Maruya M, Kawamoto S, Sitnik K, Kitamura H Agace WW and Fagarasan S: The sensing of environmental stimuli by follicular dendritic cells promotes immunoglobulin a generation in the gut. Immunity 33: 71-83, 2010.

41. Treml LS, Carlesso G, Hoek KL, Stadanlick JE, Kambayashi T, Bram RJ, Cancro MP and Khan WN: TLR stimulation modifies BLyS receptor expression in follicular and marginal zone B cells. J Immunol 178: 7531-7539, 2007.

42. Schneider P: The role of APRIL and BAFF in lymphocyte activation. Curr Opin Immunol 17: 282-289, 2005

43. Thien M, Phan TG, Gardam S, Amesbury M, Basten A, Mackay F and Brink R: Excess BAFF rescues self-reactive B cells from peripheral deletion and allows them to enter forbidden follicular and marginal zone niches. Immunity 20: 785-798, 2004.

44. Sharma A, Kiripolsky J, Klimatcheva E, Howell A, Fereidouni F, Levenson R, Rothstein TL and Kramer JM: Early BAFF receptor blockade mitigates murine Sjögren's syndrome: Concomitant targeting of CXCL13 and the BAFF receptor prevents salivary hypofunction. Clin Immunol 164: 85-94, 2016.

45. Bräuninger A, Yang W, Wacker HH, Rajewsky K, Küppers R and Hansmann ML: B-cell development in progressively transformed germinal centers: Similarities and differences compared with classical germinal centers and lymphocyte-predominant hodgkin disease. Blood 97: 714-719, 2001

46. Le Pottier L, Devauchelle V, Fautrel A, Daridon C, Saraux A, Youinou P and Pers JO: Ectopic germinal centers are rare in sjogren's syndrome salivary glands and do not exclude autoreactive B cells. J Immunol 182: 3540-3547, 2009.

47. Tussiwand R, Rauch M, Flück LA and Rolink AG: BAFF-R expression correlates with positive selection of immature B cells: Leukocyte signaling. Eur J Immunol 42: 206-216, 2012.
48. Smulski CR, Kury P, Seidel LM, Staiger HS, Edinger AK, Willen L, Seidl M, Hess H, Salzer U, Rolink AG, et al: BAFFand TACI-dependent processing of BAFFR by ADAM proteases regulates the survival of B cells. Cell Rep 18: 2189-2202, 2017.

49. Ng LG, Sutherland AP, Newton R, Qian F, Cachero TG, Scott ML, Thompson JS, Wheway J, Chtanova T, Groom J, et al: $\mathrm{B}$ cell-activating factor belonging to the TNF family (BAFF)-R is the principal BAFF receptor facilitating BAFF costimulation of circulating T and B cells. J Immunol 173: 807-817, 2004.

50. Ou X, Xu S and Lam KP: Deficiency in TNFRSF13B (TACI) expands T-follicular helper and germinal center B cells via increased ICOS-ligand expression but impairs plasma cell survival. Proc Natl Acad Sci USA 109: 15401-15406, 2012.

51. Tran NL, Schneider P and Santiago-Raber ML: TACI-dependent APRIL signaling maintains autoreactive B cells in a mouse model of systemic lupus erythematosus. Eur J Immunol 47: 713-723, 2017.

52. Novak AJ, Darce JR, Arendt BK, Harder B, Henderson K, Kindsvogel W, Gross JA, Greipp PR and Jelinek DF: Expression of BCMA, TACI, and BAFF-R in multiple myeloma: A mechanism for growth and survival. Blood 103: 689-694, 2004.

53. Jiang C, Loo WM, Greenley EJ, Tung KS and Erickson LD: B cell maturation antigen deficiency exacerbates lymphoproliferation and autoimmunity in murine lupus. J Immunol 186: 6136-6147, 2011

This work is licensed under a Creative Commons Attribution-NonCommercial-NoDerivatives 4.0 International (CC BY-NC-ND 4.0) License. 